\title{
Santuário da Liberdade
}

\author{
Mário Hoeppner Dutra \\ Desembargador do Tribunal de Justiça de São Paulo
}

Velha Faculdade:

nasceste num chão de sonhos, ternura e amor, sob o manto da humildade

- ermitério de dobres e esperanças -

legado por São Francisco.

Humildade que é beijo, redenção,

bênção aos moços enraigados na fé, jungindo presente ao passado, passado ao futuro, num surto de eternidade.

Trazes em teu abrigo a estuante realidade das esperanças segredadas nos musgos das paredes, a fé conjugada - aulistas e mestres no sopro de teu sacrário, à Luz votiva dos corações unidos. Morada de monges ascetas da verdade, com as mãos seladas a orar.

Mãos que empunham a mesma arma nas guerras crescentes de civismo e vazam na poesia de lirismo carpida, a epopéia do pão de cada dia, o louvor templário do respeito humano! Velha Faculdade:

nas tardes medrosas, rareadas de luz, cursam as pedras do teu pátio, passos silentes das almas que não morreram.

Teus muros erguem-se em torreadas de fé, barricadas aguerridas na luta, em busca de paz. Guerra abrasada no desespero dos espoliados,

* Poema declamado pelo autor por ocasião da solenidade de encerramento dos festejos do sesquicentenário de fundação dos cursos jurídicos no Brasil, realizada no salão nobre desta Faculdade a 11 de agosto de 1977. 
acendrada pelas homílias dos apóstolos espirituais, com lanças eriçadas na crença, alçadas para o azul celeste do ideal.

Velha Faculdade:

creio na terra abençoada em que nasceste, creio no sangue de tuas lutas, creio na poesia lírica de teus poetas, creio nas lendas embrechadas em tuas paredes, creio nos passos das almas que nunca morreram, creio na plangência augusta do teu campanário, creio no cântico de tuas prédicas, sagrando redenção, creio na espiritualidade votiva de tuas arcadas, creio na humildade de teu manto que te abriga, creio na tua alma, oh! gloriosa ermida: pela graça esplendente de tua história, pela bulha folgazã dos moços no pátio, pela humildade evangéliça de São Francisco, pela glória de teu aniversário, pelos cento e cinqüenta anos de relicários, pela hóstia da Justiça com que nos abençôa, pela tua alma peregrina, ungida em prece, porque és a cidadela da Glória, Santuário da Liberdade!

\section{Discurso pronunciado pelo Desembargador Mário Hoeppner Dutra por ocasião da abertura dos Festejos do Sesquicentenário, em 11 de agosto de 1976.}

Não sei de homenagem mais digna, mais alevantada, mais refletida de sacralidade, do que a admiração que se reflete na contemplação de uma obra e no exemplo que ela suscita, desvendando reminiscências.

Bem-aventurados os povos que guardam em seus escrínios esse tesouro portentoso, porque tais memórias têm a virtuosidade das lendas mitológicas que sempre inflamam nos corações, diante do exemplo que os fatos esplandecem e das imagens florescentes que neles se alteiam, a perene e sempre porfiada tarefa humana da construção do dia de amanhã.

As reminiscências são como as nuvens multifárias que se emplumam suntuosamente no azul infinito, desenhando enlevos que devaneiam o olhar e o espírito de sonhos miríficos, e como um pálio de luzes são miraculosas, fazendo brotar nas almas a 
crença contínua nas lutas pelas razões supremas de nossa existência, e, antes de tudo, pelo ser livre, pela sociedade livre, pelo respeito humano, que é a razão fundamental de nosso viver. Aos páramos divinos, somos levados nessa admiração transcendental.

No dia de hoje, o Tribunal de Justiça de São Paulo, nesta sessão solene, eleva seu olhar para as alturas e, numa prece, rende o seu tributo venerável à maior reminiscência desta terra bandeirante, cultuando a Faculdade de Direito de São Paulo, a "velha e sempre nova Academia" do Largo de São Francisco, do "Território Livre de São Francisco"

Para gáudio nosso, nesta Casa da Justiça, se levantam as primeiras exortações, iniciando as solenidades de comemoração do sesquicentenário da Fundação dos Cursos Jurídicos no Brasil, que se prolongarão até o ano próximo, quando, no dia 11 de agosto, a nossa tradicional Faculdade de Direito completará 150 anos de existência. Um século e meio de épica relevância em que soube manter o seu glorioso nome sempre envolto em auréola de prestígio e fascínio, mercê do tesouro deslumbrante que seus muros-relicários encerram.

$$
\text { *** }
$$

Nasceu num convento, no velho mosteiro de São Francisco.

Que lugar mais augusto haverá que um claustro e que maior bênção a de ter como padroeiro um santo cuja vida foi feita de humildade, respeito e amor aos seus semelhantes! Sob a égide de um ser que foi modelo de virtudes e que, na mocidade desinquieta e resplendente, ornava-se da gracilidade e da finura do espírito toscano fluído no ardor romântico dos trovadores provençais. Alma coberta de pureza que, um dia, despindo-se da roupagem nobre e das riquezas, asilou-se no ermitério de uma gruta, e, ali, na renúncia dos prazeres, soube aceitar, pelo amor de Cristo, a penúria dos desafortunados e compreender a sublimidade do beijo aos leprosos.

Foi para esse abrigo de monges, com suas arcadas solarengas e sob tão ungida proteção que a mocidade de um São Paulo provinciano foi chamada para cursar a primeira Escola de Direito do Brasil.

Havia na urbe pequenina, àquele tempo, algo que punha arrepios nas almas. Mal decorrera um lustro da Independência e ainda ecoava pelas colinas do Ipiranga o grito da emancipação política, e a Pátria, cursando rumos altanados, clamava 
pela ajuda de seus filhos, na porfia de dotar à terra livre leis próprias que atendessem aos impostergáveis ditames de sua soberania.

A nação liberta não podia preexistir no concerto das demais sem que todos, especialmente os moços, partilhassem da jornada e, para tanto, necessário era dotá-los de conhecimentos, de instrução, que somente poderiam haurir numa escola de ciências e letras.

Foi lançada a idéia precursora de sua criação, e ainda não refeitos da euforia decorrente da concretização do sonho de José BonifÁcio, outro paulista, José Feliciano Fernandes Pinheiro, depois Visconde de São Leopoldo, no dia 14 de junho de 1823, ergueu sua voz na primeira Assembléia Constituinte, apresentando à discussão o projeto de criação de uma Universidade na cidade de São Paulo.

Estava lançada a semente de uma árvore sobranceira que iria atingir as culminâncias do firmamento.

0 projeto sofreu mutações, emprestando-lhe nova redação MARTIM FRANCISCO DE ANDRADA e, guardando seu fulcro luminoso, de tropeço em tropeço, em 8 de agosto de 1826, Francisco DE PAUla Souza MELo, deputado paulista, harmonizando interesses, propôs a criação de dois cursos jurídicos, um em São Paulo, outro em Olinda, projeto que, aprovado com tal emenda e outras complementares, transfigurou-se na Lei de 11 de agosto de 1827.

Há um surto de misticismo a rondar essa obra gigantesca, e nela, toda a reminiscência dos vultos que a alentaram e, por que não dizer, toda a saudade que dos dias do passado, decorridos 150 anos, descortina-se aos nossos olhos, cintilados de alegria, e de tanta alegria, marejados de lágrimas. É que, muitas vezes, os olhos não podem ver as coisas benditas por Deus senão através das lágrimas. Lágrimas carpidas nas recordações.

No rendilhado encanto que o destino, esse mágico de surpresas, predestinou àquela Escola, um fato há, prazenteiro, que merece rememorado. Antes que o primeiro Diretor e os lentes da nossa Academia houvessem sido nomeados, foi contratado para exercer o cargo de porteiro e sineiro o cidadão LUIZ CARLOS GodINHo. Um sineiro para anunciar as horas e alertar os moços para as aulas. $\mathrm{E}$ disso se ocupava ele, grimpado no coruchéu que se erguia no alto do velho casarão, torreão que coroava o antigo templo. 
Havia qualquer coisa de predestinação no repicar daquele bronze.

Não há destino sem predestinação. Aquele sino, que fora a alma religiosa da igreja, tornara-se o arauto de todas as horas e de todos os momentos de civismo de nossa terra. $\mathrm{E}$, desse dia em diante, quem nos diz é ReYNaLdo Porchat, em primoroso discurso proferido na festa de Colação de Grau e Centenário dos Cursos Jurídicos no Brasil: - "o sino grande que tangia solene chamando os fiéis à missa, começou a bimbalhar as notas de sua alegria, repicando nas festas ruidosas da mocidade acadêmica: $O$ adro silencioso e grave, por onde passava tímida a ingênua candura das moças paulistanas sofre o fundo negro das respeitáveis mantilhas com que as matronas enchiam o vestíbulo, transformou-se em entrada álacre da rapaziada folgazã, cujos gritos joviais concertavam em contraste com o murmúrio penitente das orações piedosas"

No dia $1 .^{\circ}$ de março de 1828 , numa tarde molinheira, jubiloso, o sineiro anunciou festivamente a inauguração do curso.

Toda a vaidade paulistana, entre flores e música, em alvoroço, ocorreu ao repique alegre e bizarro, como que a vaticinar em sua vibração jogralesca que aquela festa era o início de um futuro auspicioso, em que os entraves que tanto nos aperreavam seriam desencadeados, e que haveria a frutificação das idealidades em prol da opulência de nossa gente.

Precisamente, às quatro horas da tarde, na Sala n. ${ }^{\circ}$, o Tenente-General José AROUCHE DE TOLEDo RoNDON, primeiro Diretor da Academia, presidindo os trabalhos, abriu a sessão, relevando as marcantes razões da solenidade. Em seguida, o Dr. José MARIA DE AVELAR BRotero, doutor em Direito pela Universidade de Coimbra, primeiro lente nomeado e regente da cadeira de Direito Natural, pronunciou a aula inaugural, no que se houve com garbo, em eloqüente e sublimada pregação, tal como memorizam os fastos.

Nesse dia memorável, a mão do destino começou a escrever a história arrebatadora daquele templo e a registrar em seus tombos a sortida épica de seus grandes ideais, porque as causas supremas nele encastelaram o seu ninho e não houve movimento nacional que não tivesse encontrado no abrigo de seus muros a veemência da palavra a brandir na causa e, sobretudo, ação. Poetas, romancistas, ensaistas, filósofos, juristas, comungaram o mesmo ideal de Justiça e Direito, porque aprenderam 
com os seus sacerdotes, desde a primeira aula, as regras de eqüidade que a razão natural estabeleceu entre os homens, e que foi gravada por Deus em seus corações. E, ainda, que todo povo e todo homem que tem concepção de direito e liberdade, ainda que calcado num critério puramente ideal, já é livre e sabe ser justo.

Atentai, senhores, para o tempo que passou e para o instante em que vivemos e havereis de repetir, univocamente, com Tito Lívio Ferreira: "Não sou do passado, sou da vida na dimensão do tempo irreversível", porque, como bem assinala o historiógrafo, citando Santo Agostinho, "não há passado, nem presente, nem futuro: há o tempo e a Eternidade"

Assim ponderando, podemos afirmar que a nossa Velha Faculdade guarde em si toda a sacralidade histórica de nossa terra.

Nela medraram todos os movimentos crescentes de nossa gente.

Quando os seus primeiros alunos ouviram de AvELAR BRoTERo os ensinamentos que durante quarenta anos professou na cátedra, prédicas alicerçadas na filosofia naturalista, aprenderam que a natureza social do homem provém do consagrado prolóquio: ubi homo, ibi jus, e que a juridicidade constitui um aspecto da ordem imanente, princípios que, juncados nos espíritos, explodiram no movimento abolicionista e na derrubada de um trono, porque ciência tinham de que todos os seres eram livres e que o direito divino dos reis execrava-se na superstição dos povos imaturos, ainda mesclados na ignorância.

Eram as grandes conquistas que frutificavam no cenário nacional. Os ensinamentos transmudavam-se em arietes, e o povo, pouco a pouco, despia-se das librés, alforriava-se, num cultuamento às prédicas liberais. $\mathrm{E}$ nesse ciclo momentoso, vibraram, no encanto cívico, Rio BRANCO, AFonso PENA, Rodrigues Alves, JoAquim Nabuco, Rui Barbosa, Castro ALVES e outros paladinos da liberdade, cujos nomes ficaram encastoados na heráldica da emancipação.

Aquele evolver de idéias, todavia, não cessou, e já se firmava como tradição. Bem vos assegurei que, no pergaminho da história, passado, presente e futuro se comungam, mesclando-se em Eternidade.

Crises sociais, comoções políticas, a soberania do direito afrouxada e outros fatos múltiplos, criam revezes e perigos, 
e o país, que se regia pelas bases liberais de uma Constituição, vê ameaçada a sua segurança e a sua felicidade. $O$ restabelecimento da ordem e da legitimidade, através de edificante campanha democrática, é levado ao povo que, presente nas praças públicas, ouve pela voz de RUi, Bilac, Pedro Lessa, REYNALDo PoRCHAT, FREDERICo STEIDEL o incitamento à implantação do serviço militar, do voto secreto, da justiça eleitoral e de outras reivindicações sociais, em tudo propugnando por uma democracia autêntica, sem barreiras interditas. PEREIRA LIMA, Prudente de Moraes Neto, Tomás Lessa, Francisco MesQUITA, JÚlIo DE MESQUITA FilHo acodem ao chamamento, nascendo a Liga Nacionalista, primeiro grande monumento de refinação democrática de nossa República.

Não vingou. Seus princípios e as aspirações feriam de perto os interesses bastardos da oligarquia dominante. E a cidadela foi derrubada, reduzida a cinzas, mas de seu calor, como a Fênix rediviva, emergiu o Partido Democrático, marco relevante plantado no calendário de nossa vida política. Reunidos, Paulo Nogueira Filho, Antônio Prado, Luiz A. DE Queiroz Aranha, Francisco Morato, PaUlo de Morais Barros, Cardoso de Melo Neto, J. A. Marrey Júnior, AbraÃo Ribeiro, Waldemar Ferreira e Frederico Steidel ditaram a sua programática, cumprida em sublime renovação democrática que, em eloqüente manifesto, ressoou pela nação afora.

Vingou. A Revolução veio na crista das ondas desse movimento, mas, bem cedo, decepcionou seus idealistas diante do sectarismo de moral prática que se alastrou, perdendo-se o equilíbrio das coisas no anseio de renovação, descambando-se para as transmudações radicais, com respiros à traficância de interesses pessoais que a tantos seduziu nos atropelos prófugos, tudo a exigir imediata reparação. 0 país caminhava sem lei.

1932. São Paulo ergue-se como um só homem na luta pela reconstitucionalização da Pátria. Marcha fascinante, em que nossos irmãos templários transmudaram em quartel o vetusto convento, dali partindo os primeiros soldados da lei.

Nem sei o que mais dizer, diante de tudo quanto foi cantado, dessa epopéia maravilhosa, senão que mestres e alunos, corações unidos, armas em punho, comungando a mesma fé e rezando pelo destino de São Paulo e do Brasil, caminharam para as trincheiras da lei e escreveram com o seu sangue uma das páginas mais sublimes de nossa história. 
Hoje, na sombra das Arcadas, com uma coroa de louros, está plantado o monumento ao Soldado Constitucionalista, sagrada lembrança dos que lutaram e morreram pela liberdade. Nele, o buril requintado cinzelou, em caracteres flavos, a elegia respliendente de patriotismo, entoada por TOBIAS BARRETO :

"Quando se sente bater

No peito a heróica pancada,

Deixa-se a folha dobrada

Enquanto se vai morrer

Vencidos, mas não subjugados, tinha-se a impressão de que a história parara. Vigia o regime do arbítrio e da opressão, caudilhismo que se extremou com o trancar das portas do parlamento e o arrolhamento da imprensa.

O sonho de ontem transfigurava-se em tormentoso pesadelo. Com fel, São Paulo pagava o tributo do sacrifício por um ideal. E o amordaçamento das vozes era cumprido nas prisões arbitrárias e atrabiliárias, com o viso de esmagar consciências, açaimar paixões, eliminar adversários, apodando-se os veradeiros patriotas como inimigos da Nação.

As masmorras rangiam seus gonzos e nelas foram esquecidos, entre outros apóstolos do movimento que minha memória manqueja, Waldemar Ferreira, Ernesto Leme, Soares DE Melo, Cristiano Altenfelder, MoACyr Amaral Santos, Antônio Carlos de Abreu Sodré, Roberto de AbreU Sodré, Francisco Mesquita, Júlio de Mesquita Filho e Aureliano LEITE, até o dia em que, juntamente com outros companheiros de luta, ganharam o florão do exílio.

Àquele tempo, o mundo estava impregnado do credo totalitarista, que avassalava todas as fronteiras e que se fez ouvir entre nós num vozear imaturo, verdoengo. Para os seus panfletários, o Estado era um fim e não um meio, e a imposição de um governo Todo-Poderoso exigia o aniquilamento do indivíduo. Vivia-se a época do antiliberalismo.

Tudo estava a exigir manifesto e público repúdio. $\mathrm{E}$ a clarinada vibrou. Com a prisão do estudante HÉLIo MotA, então Presidente do Centro Acadêmico "XI de Agosto", um grito oportuno ecoou através do Manifesto à Nação de $1 .^{\circ}$ de novembro de 1943 , em que se exigia uma definição do país em face da agressão fascista.

Redigiu-o Luís ARrobas Martins, seguindo-se à sua assinatura cerca de duzentas outras, convictos todos de que aquela 
atitude se impunha perante o nosso povo para que ele continuasse digno de suas tradições viris, lutando ao lado das nações livres, batalhando pela preservação dos valores humanos e para que se integrasse na sua linha histórica, expurgando desta terra os fermentos ideológicos que o fascismo estrangeiro e indígena lhe inoculara.

Como vedes, mais um feito de inolvidável figuração cívica, cuja lembrança foi traçada por BRASIL BANDECCHI, imperecedouramente, nas páginas da "Revista do Instituto Histórico e Geográfico", de São Paulo, e que no bronze imorredouro de uma placa ficou embrechada no saguão da Velha Academia.

Reconquistada a democracia, volta a Pátria aos dias de paz e progresso, mas, para infelicidade de todos os brasileiros, efêmera fora a conquista. A renúncia sibilina do último Presidente da República sufragado pelas urnas populares atirou-nos ao caos e estaríamos reduzidos a um vasto aglomerado de homens estandartizados, erradicados de almas, a fervilhar numa sociedade escatológica, não fora a marcha vitoriosa de um povo já conscientizado em seus anseios de liberdade.

$* * *$

Senhores:

AlCÂNTARA MACHADo, prefaciando uma coletânea de poemas escritos por estudantes de direito, observou que a Velha Academia tinha três portas principais, encimadas por três pedaços de mármore branco, e que foi a mocidade de seu tempo que os colocou na fachada do prédio e nele mandou insculpir três nomes.

"Seria natural" - diz ele - "tratando-se de uma escola de direito, que os homens assim consagrados como numes tutelares fossem escolhidos dentre os juristas, mestres ou discípulos do insigne instituto: RUI, TeIXeIRA DE Freitas, Ribas, Ramalho, Pimenta Bueno . Mas o que víamos não era a sua nobreza de centro de elaboração e irradiação do pensamento jurídico; e sim o prestígio, que a tradição lhe atribuíra, de filial do Parnaso em terra brasileira. Por isso, em vez de três jurisconsultos, evocaram uma trindade de poetas: Álvares DE Azevedo, Castro Alves, Fagundes VARELA."

De fato, a humanidade sonha pelos poetas e neles habita um Deus que os inspira e os alenta com as sementes da inspiração celestial. 
No dia de hoje, aniversário da nossa Faculdade, os versos afloram em buquês multicores. São os beijos à mãe amada, - louvor crescente das almas transcendentes onde fervilha sempre o coração coberto de ternura e amor. E essa glorificação vicejante faz-se sentir no "Canto de Glória", de Oliveira RIBEIRo NETO, neste rendilhar de plumas espirituais:

"Minha Faculdade, velho ninho de águias, fonte esclarecida do ideal clarão, já vinte anos antes da República, mandaste teus filhos conduzir o archote, lúcidos pregoeiros da renovação. E quando o Brasil, trêmulo e humilhado, sem lei e sem rumo, ia escravizado, engolindo as lágrimas duma longa noite sem o breviário da Constituição, foi tua coragem, minha velha escola, que fez das Arcadas muros de defesa, que tornou as taipas em fortins de guerra, e pôs no teu peito o fanal da luta do ânimo paulista a mostrar a senda duma liberdade sem ser usurpada. Os teus dois patronos foram teu exemplo, pois foi São Francisco que te deu a fibra, pois que foi São Paulo que te deu a espada! Hoje que estás rica, de pedra vestida, toda rendilhada qual noiva garrida do São Paulo novo dos arranha-céus, hoje que não dormes sob os longos véus de névoa e de garoa do São Paulo antigo de ruas estreitas e falar pausado, eu confio e espero em tua mocidade que é a mesma sempre, velha Faculdade, pois Rui, e Nabuco, e Rio Branco e mil outros que deram à pátria seu nome grandioso enchendo de luzes páginas da História, vão mostrando aos moços, por felicidade, que o teu nome sempre, minha Faculdade, é a melhor das rimas para Liberdade é a maior das chamas para o altar da Glória!"

A poesia tem em si algo de divino que alteia a realidade das coisas, envolvendo-as nas inspirações do coração. Bem se disse que a humanidade sonha pelos devaneios dos poetas.

Bilac escreveu que "os poetas são estuários, em que se vêm confundir as torrentes de ideais e de sentimentos que 
agitam as idades; são espelhos em que se vêm refletir e concentrar os feixes de raios ardentes em que abrasa o ideal humano"

É bem verdade. $O$ coração da mocidade comprimiu pelos corredores das Arcadas versos que a cobriram de glória. E PAULo Bomfim, comungando o coro mavioso e esplêndido de seus irmãos templários, ergueu para os céus, em evocativa memória, seu "Canto de amor à Faculdade", entalhando-o nas pedras do monumento cintilar onde o sol nunca descamba sua luz no ocaso.

Ouçâmo-lo :

Somos passado e futuro, Presente de indagações, Pedra de sonhos crescendo

No Largo de São Francisco;

Canção de velhas violas

Embalando cosmonautas, Arcadas que o tempo arcou

Para que deles partissem

Flechas de amor e protesto,

Setas com plumas de dor

$\mathrm{E}$ pontas de inconformismo.

- Em vossos olhos o olhar

Das gerações que partiram,

Das gerações que virão.

Em vossa luz a palavra

Estrela de tanta noite!

Em vossas mãos a bandeira

Bordada por vossos mortos,

Bandeira que é céu de Pátria,

Terra prenhe de esperança,

Canção de guerra e de paz

$\mathrm{Na}$ audácia de vossas lanças!

- Pela memória da terra,

Pelos segredos do Pátio,

Pela prece das Arcadas,

Pela aurora das paredes,

Pelo mistério das salas,

Pelo grito das estátuas,

Pela voz da escadaria,

Pela clareira do Largo,

Pela bênção dos telhados,

Pela alma dos poetas 
Pelo martírio de heróis,

Por tudo que é São Francisco,

Por tudo que é mocidade,

Seja nossa vossa causa,

Seja vossa nossa luta,

E por paixão, rebeldia,

Sede de amor, de justiça,

Viva em nós a rosa agreste

$\mathrm{E}$ escreva com seus espinhos

E grave com nosso sangue,

Em muros, mares e ventos

A palavra - Liberdade!

Bem vêdes que o sino do prisco Mosteiro não se quedou à missão primeira de sacudir as horas, alentando a rapaziada bulhenta para a confraternização das aulas. Em todos os tempos, sentinela alerta, - sino sagrado da redenção! - seu dobre, em precípites vozes argentinas, congregou seus filhos para os grandes momentos cívicos da Pátria. O sonar de seu bronze ecoou pelas cumeeiras do Jaraguá e venceu todas as herdades do torrão natal, a todos conclamando para a luta e para a glória. E nos instantes de paz e de quietude espiritual, em meio à claridade cambiante e morrediça dos crepúsculos, seu tanger sereno se eleva para as alturas, concitando à prece, na beatitude dulcífica das ave-marias.

Hoje, galharda e festivamente, na gloriosa hermida, seu bimbalhar ressoa pelas homílias de seus apóstolos e pelo canto de seus poetas.

Irreversível em suas aspirações, infensa à transmudação do tempo, tantas vezes ímpio!, a Velha Faculdade mantém acesa a pira de seus ideais e guarda no musgo de seus muros o relicário de sua história, a tradição dos que ali viveram, dos que vivem e dos que hão de viver, sem que força alguma possa usurpá-la, porque nela se eleva o altar da Pátria!

Cidadela incólume! Cidadela da Liberdade! 